Pedagogía y Saberes No. 51

Universidad Pedagógica Nacional

Facultad de Educación. 2019. pp. 89-102

\title{
Aprendizagem: o imperativo de uma nova ordem econômica e social para o desenvolvimento
}

\section{Artículo de investigación}

Learning: the Imperative of a New Economic and Social Order for Development

Aprendizaje: el imperativo de un nuevo orden económico y social para el desarrollo

Carine Bueira Loureiro* Maura Corcini Lopes**

Para citar este artículo:

Loureiro, C.; Lopes, M. (20199. Aprendizagem: o imperativo de uma nova ordem econômica e social para o desenvolvimento. Pedagogía y Saberes, 51, 89-102.

Profesora del Instituto Federal Rio Grande do Sul (IFRG), Doctora en Educación de la Universidade do Vale do Rio dos Sinos (UNISINOS) e investigadora del Grupo de Estudos e Pesquisa em Educação, Matemática e Tecnologias.

Correo electrónico: carine.loureiro@poa.ifrs.edu.br;

Código orcid: https://orcid.org/0000-0002-3329-2535

** Profesora de la Universidade do Vale do Rio dos Sinos (UNISINOS), Doctora en Educación de la Universidade Federal do Rio Grande do Sul (UFRGS) e investigadora del Grupo de Estudos e Pesquisa em Inclusão (GEPI).

Correo electrónico: maura@unisinos.br

Código orcid: https://orcid.org/0000-0002-2419-9208 


\section{Resumo}

O objetivo deste artigo é problematizar como o conceito de desenvolvimento e o de aprendizagem se articulam, subjetivando os indivíduos para uma cultura digital. A pesquisa documental permitiu a identificação de dois eixos analíticos, a saber: desenvolvimento e ensino e aprendizagem. Utilizase dos conceitos de discurso e subjetivação para demonstrar que, no cerne dos discursos que aliam o desenvolvimento à aprendizagem, está a constituição do Homo œconomicus discentis accessibilis.

\section{Palavras-chave}

tecnologias digitais; aprendizagem; desenvolvimento; prática discursiva; subjetivação

\section{Abstract}

The aim of this paper is to discuss how the concepts of development and learning are related, subjectivating individuals for a digital culture. The documental research provided the identification of two analytical categories, which are: development, and teaching and learning. The concepts of discourse and subjectivation are used to demonstrate that, in the core of discourses that correlate development and learning, lies the constitution of the Homo œeconomicus discentis accessibilis.

\section{Keywords}

digital technologies; learning; development; discursive practice; subjectivation

\section{Resumen}

El objetivo de este artículo es problematizar como los conceptos de desarrollo y de aprendizaje se articulan, subjetivando a los individuos hacia una cultura digital. La pesquisa documental permitió la identificación de dos ejes analíticos, a saber: desarrollo y enseñanza y aprendizaje. Se utilizan los conceptos de discurso y subjetivación para demostrar que, en el meollo de los discursos que alían el desarrollo al aprendizaje, se encuentra la constitución del Homo œeconomicus discentis accessibilis.

\section{Palabras clave}

tecnologías digitales; aprendizaje; desarrollo; práctica discursiva; subjetivación 


\section{Introdução}

A capacitação de recursos humanos, questão fundamental e urgente, é, sem dúvida, um dos principais fatores de desenvolvimento de uma nação. Essa capacitação deverá estar voltada para a preparação da sociedade brasileira para conviver com a era da informática [...]. (Proninfe, 1989, pp. 21-22).

Os dados mundiais sobre educação permitem associar, de um modo geral, situações sociais críticas a países que não oferecem educação básica de qualidade a suas populações, não priorizando, dessa forma, a dimensão humana do desenvolvimento. Nas sociedades democráticas que dispõem de fortes programas de capacitação de recursos humanos e sistemas educacionais em expansão, geralmente o cenário é outro: estabilidade econômica e menores desigualdades sociais decorrem de um progresso baseado cada vez mais no uso intensivo de tecnologia e na circulação cada vez mais rápida de um crescente volume de informações. (Proinfo, 1997, p. 1).

[...] espera-se que o Prouca também apoie a integração da escola com a comunidade, favorecendo não apenas a sua inclusão no mundo digital, mas principalmente oferecendo elementos para que desenvolva processos mentais mais elaborados, aumentando as suas chances de êxito/autonomia na sociedade ativa e produtiva. (Prouca, 2010a, s/p.).

O impacto da tecnologia nas relações pessoais, sociais e econômicas é sensível e dinâmico. 0 tempo todo, somos obrigados a adaptar nossas vidas às transformações da era da informação e do conhecimento, que evolui em grande escala e ritmo acelerado. A Educação - base das competências e das habilidades requeridas pelas novas formas de estudar, de trabalhar, de nos divertirmos - pode ser imensamente beneficiada pela tecnologia. Porém, não basta criar infraestrutura para levar tecnologia às escolas. As práticas pedagógicas devem ser orientadas para a inovação nas salas de aula. (Proiec, 2018a, p. 2).

Os excertos que abrem este artigo têm uma dupla função: retratar o corpus analítico da pesquisa ${ }^{1}$ da qual resultou o presente texto e dar o tom da discussão que tecemos aqui. Mais especificamente, pretendemos chamar atenção para os conceitos de

1 Reflexão resultante de investigação concluído. Projeto: Ciclos formativos pedagógicos: ensino e aprendizagem em matemática mediado por tecnologias digitais, realizado durante estágio pós-doutoral na Universidade do Vale do Rio dos Sinos, sob financiamento do CNPQ, Brasil (167385/20178) e do Instituto Federal Rio Grande do Sul. desenvolvimento, de aprendizagem e, associado a estes, para o conceito de vida a-orgânica. Tais conceitos serão mais bem explorados na sequência do texto.

Adiantando um pouco a discussão para que as reflexões iniciais feitas neste artigo tenham sentido, o conceito de desenvolvimento pode abarcar distintas dimensões econômicas, sociais, individuais, políticas, digitais, etc. Para nós, neste momento, interessa tanto uma dimensão individual e social quanto uma dimensão política e inter-relacional, pois ambas estão indissociavelmente imbricadas no século XXI.

Para Klaus (2011), o desenvolvimento pode ser "medido pelo capital investido nas pessoas" (p. 169). Somado a esta compreensão, é possível dizer que o desenvolvimento também pode ser medido e percebido pelo que é gerado nas relações. Trata-se de um conceito flexível, usado para medir resultados, bem como para dimensionar a potência criativa de coletivos virtuais-colaborativos. Portanto, por tal conceito, abarcamos tanto a dimensão físico-espacial e individual quanto a dimensão das virtualidades e temporal.

O desenvolvimento, tomado na articulação entre elementos de uma sociedade moderna e de uma sociedade de controle, nos faz perceber a quão necessária ainda é a ação disciplinar escolar, bem como a ação biopolítica, sobre a vida da população. Porém, tais ações necessitam ser reconfiguradas e recriadas para que possam ser orquestrados os fluxos de produção de ativos (in)tangíveis no século XXI.

No século XXI, tanto a disciplina quanto a biopolítica continuam sendo imprescindíveis. Todavia, faz-se necessário atualizar a compreensão de ambas para entendermos como a variável contemporânea tempo opera esmaecendo (e não fazendo desaparecer) a variável moderna espaço na determinação de uma cultura tecnológica de tipo digital e caracterizada pela virtualidade. Compondo nossa compreensão de virtualidade, estão conceitos, tais como: flexibilidade, desterritorialidade, provisoriedade, velocidade, público e vida a-orgânica, entre outros.

Por vida $a$-orgânica, entende-se a vida não de um indivíduo biológico, embora este seja fundamental e necessite ser educado para compor de forma colaborativa as relações deste tempo, mas eventos virtuais. Dito de outra maneira, uma vida a-orgânica é tanto resultante quanto criadora da multiplicidade, da molecularidade, da rede e da descentração do indivíduo como autor-originário. Ela se constitui nos intervalos relacionais e na formação constante de públicos². Eis um dos desafios para a escola con-

2 Para Lazzarato (1999), “[...] é possível definir o público como modelo mais dinâmico e mais desterritorializado e, portanto, 
temporânea, bem como uma das razões para os investimentos de Estado na escola e na educação digital da população.

Este tipo de desenvolvimento que articula interesses políticos, econômico-financeiros, individuais, sociais e tecnocientíficos, medíveis e/ou percebíveis, implica a operacionalização inicial de investimentos em políticas educacionais capazes de fomentar a criação de condições para a geração do novo e/ou da inovação. Porém, investir em políticas educacionais visando a instrumentalizar a população para o uso de tecnologias e para o desenvolvimento de competências digitais é uma parte do que é preciso ser feito no Brasil. Paralelo a este investimento, está a necessidade urgente de diminuição das desigualdades. Portanto, minimizar as desigualdades é condição sine qua non para que possamos falar de desenvolvimento econômico, político, social, tecnológico-digital, etc.

Dentro do contexto de desigualdade anunciado, a escola disciplinar brasileira está convocada no presente a reinventar-se, e não "somente" a atualizar-se. Com isso queremos dizer que não é suficiente incorporar aparatos tecnológicos às escolas ou promover o acesso aos recursos digitais. É preciso considerar a necessidade de pensar o uso das tecnologias na educação como recurso para ampliar a formação ética e estética, para produzir possibilidades de pensar de outras formas, a partir de novas perguntas. A maquinaria oitocentista não é inclusiva, tampouco é flexível o suficiente para romper com suas paredes e promover a aprendizagem de qualquer um a qualquer tempo. Para Sibilia (2012), o problema mais complexo e difícil que temos a enfrentar no contexto educacional da América Latina é redefinir a escola "como espaço de encontro e diálogo, de produção de pensamento e decantação de experiências capazes de insuflar consistência nas vidas que as habitam" (p. 211).

Redefinir a escola exige que questionemos, mais uma vez, a sua necessidade no presente e em um futuro próximo. Exige que a definamos menos do que um espaço de confinamento e mais como tempo-potência para o encontro e a aprendizagem colaborativa. Para isso, discutir as competências para o século XxI tornase importante, assim como a virtualidade como condição para o desenvolvimento individual e coletivo.

como modelo que tende a comandar e a reorganizar os outros. O público, efetivamente, é um evento" (p. 86), constituído pelo "tempo, a velocidade, a ação à distância" e, acrescentaríamos ao que já foi apontado, pelo interesse coletivo de consumo. Como tal, o público é um elemento frágil em termos de continuidade, materialidade, e extremamente forte e potente em termos de geração de necessidades e de inovação.
Das relações que parecem exigir a reconfiguração da escola e fazer emergir as condições de possibilidade para pensarmos em um éthos de digitalidade no presente, a aprendizagem torna-se condição central para o desenvolvimento do Homo œeconomicus discentis accessibilis, conforme figura subjetiva nomeada por Loureiro e Lopes (2017). Segundo as autoras, tal figura subjetiva, forjada em redes neoliberais renovadas constantemente pelas práticas do capitalismo de tipo econômico-financeiro, além de assumir a condição de aprendiz para toda a vida, bem como a de virtualidade de sua existência, deve estar permanentemente conectada ou disponível para acessar e ser acessada.

Para educar o Homo œeconomicus discentis accessibilis, urge questionar a escola, exigindo-se dela outros formatos, talvez mais focados no tempopotência virtual de criação do novo do que no espaço de confinamento disciplinar. Outras possibilidades de aprendizagem, menos pautados no tempo e no espaço, mas com uma condução pedagógica mais afinada à cultura digital. Diante de tal desafio contemporâneo de pensar a escola como instituição ativa em uma forma de vida marcada e definida em grande parte pela digitalidade, torna-se importante problematizarmos os discursos ${ }^{3}$ que estão configurando os rumos da educação no presente. Entre os discursos vistos circulando nas práticas de governamento de distintos governos brasileiros, estão: os econômicos de tipo financeiro, os tecnológico-digitais, os da aprendizagem e os da formação por competências, todos articulados pelas práticas de desenvolvimento.

A pesquisa documental que está na origem deste artigo tinha como interesse principal tensionar os discursos presentes nas práticas de informática na educação. Para tanto, foram analisados quatro programas operacionalizados no Brasil entre os anos 1989 e 2017. Devido aos limites de espaço para o desenvolvimento de uma problematização minimamente consistente, neste artigo, procedemos à análise de quatro dos programas referidos acima. São eles: Projeto Programa Nacional de Informática Educativa (Proninfe), lançado em 1989; Programa Nacional de Informática na Educação (Proinfo), lançado em 1997; Programa Um Computador por Aluno (Prouca), lançado em 2005; e Programa Inovação Educação Conectada (Proiec), lançado em 2017. Por meio do Proninfe o Governo brasileiro pretendia "iniciar o processo de universalização do uso de tecnologia no sistema público de ensino" (Proninfe, 1989, p. 3).

30 conceito de discurso constitui uma de nossas ferramentas metodológicas de pesquisa. De inspiração foucaultiana, ele remete a conjuntos enunciativos que constroem os objetos sobre os quais falam. (Foucault, 2009). 
Para atingir tal objetivo, o programa propunha-se a ofertar cursos de formação continuada a professores da rede pública de educação básica. No âmbito desta política, o ferramental tecnológico era visto como "instrumento capaz de enriquecer estratégias pedagógicas e de estimular o surgimento de novas metodologias" (Proninfe, 1989, p.9). Evidencia-se nos documentos do Proninfe certo comprometimento com a "melhoria da qualidade do processo de ensinoaprendizagem" (Proninfe, 1989, p.21).

Quase dez anos depois, Proinfo amplia as pretensões dimensionadas anteriormente no Proninfe e propõe-se a "universalizar o uso da tecnologia de ponta no sistema público de ensino" (Proinfo, 1997, $\mathrm{s} / \mathrm{p}$.) e a promover a informatização da escola pública. Para tanto, o programa viabiliza a equipagem de escolas públicas com laboratórios de informática. "Melhorar a qualidade do processo de ensino-aprendizagem" (Proinfo, 1997, p. 21) a partir da disponibilização de computadores a professores e alunos também é uma das propostas do Proinfo. A busca pela universalização do uso das tecnologias deixa de ser prioridade e em 2005 o Prouca amplia essa noção e a meta passa a ser a promoção da "inclusão digital pedagógica e o desenvolvimento dos processos de ensino-aprendizagem de alunos e professores das escolas públicas brasileiras, mediante a utilização de computadores portáteis, denominados laptops educacionais" (Prouca, 2010, p. 1). Uma das bandeiras do Prouca era a ampliação dos espaços escolares e desse modo, propõe o uso dos dispositivos computacionais para além da sala de aula e, mais do que isso, da escola. Os "laptops educacionais" poderiam ser utilizados pelos alunos em suas residências, propiciando com isso que um número maior de pessoas estivesse apto a participação na cultura digital.

Diferentemente dos dois últimos programas que propunham o acesso aos equipamentos, o Proiec, lançado em 2017, propõe-se a "apoiar a universalização do acesso à internet de alta velocidade $\mathrm{e}$ fomentar o uso pedagógico de tecnologias digitais na educação básica" (Proiec, 2018, p. 1, grifos nossos). 0 foco desta política não está mais no acesso ao equipamento, mas ao acesso à conexão, à participação na rede, à inserção nos modos de vida próprios da cultura digital. Mais do que isso, enquanto nos programa que o antecederam era possível identificar o interesse pelo processo de ensino e de aprendizagem - embora tal preocupação fosse manifestada por meio do binômio "ensino-aprendizagem", a palavra "ensino" estava presente, indicando a participação de alguém, no caso o professor, responsável pela condução do processo de aprendizagem - no Proiec, a ênfase recai está na ampliação das oportunidades de aprendizagem. 0 acento dado pelo Proiec ao acesso à internet e às condições de aprendizagem nos sinalizam uma mudança relevante desta política em relação às anteriores. Mais do que isso, o destaque às "ações de inovação" mobilizados por meio dos discursos do Proiec sinalizam para nós o vínculo, que parece cada vez mais fortalecido na atualidade, entre a noção desenvolvimento e a capacidade de aprendizagem notável nos discursos que promovem o uso das tecnologias

Nosso objetivo central neste artigo é perceber e problematizar como o conceito de desenvolvimento e o de aprendizagem se articulam, subjetivando os indivíduos para uma cultura digital.

Embora os Programas analisados tenham sido construídos com vistas a fomentar o uso de tecnologias digitais na educação, acreditamos que os discursos que geram essa necessidade ultrapassam tais documentos, justificando em boa parte suas existências. Daí a importância da abordagem metodológica utilizada na pesquisa. Nosso interesse não estava centrado em uma análise dos textos documentais, mas nos discursos que os constituíam, gerando práticas vividas por docentes e estudantes nas escolas. Também nos interessava perceber a indução de práticas de subjetivação capazes de criar tipos específicos de sujeitos virtuais possíveis. Sendo assim, procedemos a uma analítica foucaultiana do material, operando com dois conceitos-ferramenta metodológicos: o de discurso e o da subjetivação ${ }^{4}$.

A fim de desenvolvermos a problematização proposta, dividimos este artigo em quatro seções, a partir desta introdução. Na primeira seção, trazemos os desdobramentos da noção de desenvolvimento a partir da segunda metade do século Xx. Na segunda seção, damos continuidade a essa discussão e mostramos como a ideia de desenvolvimento aparece enaltecida nas políticas direcionadas para a disseminação do uso das tecnologias na educação. Nessa seção, também apresentamos os materiais de pesquisa e conceituamos as ferramentas utilizadas na analítica desenvolvida. A terceira seção é dedicada à problematização do conceito de aprendizagem, que, entendemos, se constitui na atualidade em uma necessidade cara aos sujeitos, no intento de desenvolverem a si mesmos. Na última seção, tecemos nossas considerações sobre a relação que se estabelece e se fortalece entre aprendizagem e desenvolvimento e argumentamos

O conceito de subjetivação também se constituiu em uma de nossas ferramentas metodológicas de trabalho sobre os materiais. Para Foucault, as práticas de subjetivação são aquelas que fazem os sujeitos curvarem-se aos outros e a si mesmos, tomando formas subjetivas específicas. (Foucault, 1999). 
que a constituição do Homo œconomicus accessibilis adquire centralidade na articulação entre desenvolvimento e aprendizagem em uma vida a-orgânica.

\section{As condições do desenvolvimento}

A lógica do desenvolvimento emerge, conforme explica Arturo Escobar (2007), a partir de 1945, quando dois terços do mundo são definidos como pobres. Antes, nos séculos XVIII e XIX, era a noção de progresso que pautava as relações econômicas e sociais (Foucault, 2008). A globalização da pobreza torna-se, portanto, a partir da segunda metade do século Xx, um problema mundial. A solução para reverter este quadro seria reproduzir a realidade das nações desenvolvidas naquelas consideradas subdesenvolvidas, ou de Terceiro Mundo. Assim, com o intuito de contornar tal situação e alavancar o desenvolvimento econômico, países reconhecidamente desenvolvidos, com destaque para os Estados Unidos, passam a delinear e pôr em prática estratégias de controle e regulação das ações de países - entre eles, o Brasil - onde os altos índices de pobreza da população, a baixa produtividade da indústria e as altas taxas de desemprego e, por conseguinte, de violência eram considerados preocupantes.

Para compreender como a lógica do desenvolvimento se expande e se torna fundamental, a ponto de ser central na formulação de políticas públicas, especialmente daquelas voltadas para a educação básica, é preciso "olhar para as relações entre os sistemas e não para os sistemas em si mesmos" (Escobar, 2007, p. 78, tradução nossa). Pois é a relação entre as instituições, os processos socioeconômicos, as formas de conhecimento, os fatores tecnológicos, etc. que nos permite a criação sistemática de objetos, conceitos e estratégias e que, consequentemente, determina o que pode ser dito e pensado (Escobar, 2007). Em outras palavras:

o sistema de relações estabelece uma prática discursiva que determina as regras do jogo: quem pode falar, de qual ponto de vista, com que autoridade e segundo quais qualificações; define as regras a seguir para o surgimento, denominação e eventual transformação da pobreza (Escobar, 2007, p. 78, tradução nossa).

Nesse sentido, e também para nos permitir explicar como as políticas voltadas para a propagação do uso das tecnologias na educação levam adiante a noção de desenvolvimento, interessa-nos fazer um recorte nos acontecimentos que marcam a busca, por parte do Estado brasileiro, por esta condição que emerge a partir da Segunda Guerra Mundial.
Desde, pelo menos, os anos 30, a ideia de desenvolvimento, no Brasil, esteve atrelada à industrialização e urbanização. Essa concepção foi reforçada no governo do presidente Juscelino Kubitschek, cujo objetivo era fortalecer a industrialização com a finalidade de promover o desenvolvimento do país. De meados da década de 1960 ao início dos anos 1980, no transcurso do governo militar, manteve-se boa parte das políticas voltadas para o desenvolvimento do País postas em funcionamento por Juscelino Kubitschek. No entanto, naquela ocasião, a necessidade de conferir autonomia à indústria nacional e de desenvolver tecnologia própria impulsionou a implantação de políticas que visavam à expansão das tecnologias em diferentes setores do país. Em suma, no período entre meados de 1950 e 1980, os investimentos no desenvolvimento do país foram caracterizados, especialmente, pelo desenvolvimento da indústria nacional. Tratava-se de uma época em que o modelo de Estado Desenvolvimentista havia se consolidado, fazendo com que as práticas de governamento - definidas por Foucault como as práticas que organizam o campo de ação dos sujeitos - fossem regidas por um estado centralizador, que comandava o crescimento focado no mercado interno, com forte proteção às empresas nacionais e pouca abertura à concorrência internacional, o que resultou em promoção do desenvolvimento à custa da fragilidade econômica (Dathein, 2008).

Naquele período, como não havia preocupação com geração de tecnologia própria e o Estado estava voltado para o mercado interno, o desenvolvimento tecnológico brasileiro ficou defasado, pois os esforços haviam sido direcionados apenas para a preparação de mão de obra para a produção em massa, e não foram feitos investimentos no sentido de criação, inovação e desenvolvimento. Assim, começam os investimentos em programas para a preparação e capacitação da população para as novas configurações do mundo do trabalho - mais pautado na imaterialidade do que na produção - e das formas de vida que se constituem na contemporaneidade - regidas pelo consumo e pela competição. Em consequência disso, as discussões sobre o uso de computadores na educação tornam-se pauta constante das agendas políticas, e o governo brasileiro começa a demonstrar interesse em desenvolver ações que viabilizem o uso de computadores em escolas públicas.

A necessidade, portanto, de disseminar o uso das tecnologias na educação emerge no contexto de uma série de acontecimentos que se dão em âmbito mundial e que ocasionam mudanças significativas na economia, na política e, consequentemente, na sociedade. Fatores próprios da globalização, como 
o fortalecimento do dólar e a reestruturação produtiva promovida pelas tecnologias da informação e comunicação, impactaram consideravelmente sobre a economia brasileira, fazendo com que o plano de desenvolvimento tivesse de ser revisto. Estes acontecimentos criaram um clima propício para reformas de caráter estrutural no país (Farias, 2008), entre elas, a instituição de estratégias para atingir a estabilidade econômica. Para tanto, o modelo de desenvolvimento centrado no crescimento do mercado interno, com baixo índice de abertura econômica e proteção extremada contra a concorrência internacional, sustentado pelo Estado Desenvolvimentista, precisava ser alterado (Dathein, 2008).

Desse modo, o papel do estado vai sendo redefinido, e a condução do país deixa de estar pautada em um modelo de estado com poderes ilimitados. 0 padrão de desenvolvimento a ser atingido tinha como uma de suas principais características o empenho do governo brasileiro na criação e na manutenção de um ambiente amigável com os países dos cinco continentes e, especialmente, com o mercado externo. Assim, uma série de modificações - próprias da lógica neoliberal: reestruturação do modelo de industrialização, abertura de mercado, busca pela estabilidade econômica, relações multilaterais, etc. - é instituída no Brasil, a fim de que o país se insira no "novo paradigma de desenvolvimento" (Farias, 2008, p. 27).

0 padrão de desenvolvimento em questão tem suas raízes no neoliberalismo, que, enquanto racionalidade, organiza tanto a ação dos governantes quanto a conduta dos governados (Dardot; Laval, 2016). 0 neoliberalismo, razão do capitalismo, constitui-se em um conjunto de discursos, práticas e dispositivos que tem na concorrência o motor para a condução das condutas e no modelo da empresa a forma de subjetivação (Dardot; Laval, 2016). Nesse contexto, em que, para atingir o almejado padrão de desenvolvimento, os sujeitos precisam capitalizar a si mesmos para potencializar suas chances de concorrência, Klaus (2016) defende que a educação passa a ser vista como investimento. Nessa mesma linha, Moreira e Kramer (2007) argumentam que, entre as modificações que se estabeleceram, a "versão neoliberal da globalização" (Moreira; Kramer, 2007, p. 1041) está refletida na pauta das políticas educacionais brasileiras - entre elas, as políticas voltadas para o uso das tecnologias na educação (Moreira; Kramer, 2007). Desse modo, em 1989, é formalizada a primeira política pública voltada para a propagação do uso das tecnologias na educação, e investimentos desta natureza estenderam-se até as primeiras duas décadas do século XXI.
O desenvolvimento cada vez menos parece estar relacionado com a capacidade de produção industrial de um país e mais com a potência de inovação, de criação, de articulação entre cérebros. A educação como investimento não se pauta mais na instrumentalização dos indivíduos para o uso das tecnologias. Isso acontecia nas políticas de 1989 e de 1997, Proninfe e Proinfo, respectivamente. 0 tipo de investimento feito a partir dos primeiros anos do século XXI, com o Prouca, e estendido até a atualidade, com o Proiec, atrelado ao desenvolvimento do país, é da ordem da instrumentalização cognitiva dos indivíduos. Com investimentos dessa ordem, os estudantes são cada vez mais instrumentalizados para que eles próprios possam criar as condições virtuais para compor cenários de aprendizagem colaborativos. Portanto, em nossa pesquisa, evidenciamos o alargamento da noção de desenvolvimento por meio das políticas voltadas para a inserção e uso das tecnologias digitais na educação.

\section{Os caminhos da aproximação entre desenvolvimento e aprendizagem pela via das tecnologias na educação}

Embora a primeira política pública direcionada para a disseminação das tecnologias na educação tenha acontecido em 1989, ainda nos primórdios dos anos 1980, o Brasil começa a fazer investimentos mais significativos do que fizera anteriormente em ações para a inserção e uso de computadores em escolas públicas. 0 Projeto Educom, pioneiro nesse processo, foi um projeto piloto que iniciou em 1981 por meio de propostas independentes de cinco universidades brasileiras, as quais, ainda que contassem com financiamento público, foram responsáveis pela execução de seus projetos. 0 objetivo do Educom era imprimir o uso do computador como uma "ferramenta para a aprendizagem" (Nied, 1983, p. 2). Na sequência, porém com diferenças significativas em relação ao Educom e em forma de política pública, em 1989, foi lançado o Proninfe, que consistia em ações para a disseminação da informática no processo educacional. O Proinfo ${ }^{5}$, que iniciou em 1997, além da propagação da informática na educação, teve como principal propósito a implantação de laboratórios de informática em escolas públicas. Diferentemente do Proinfo, que

5 Aliado ao Proinfo e como forma de expansão dos investimentos feitos por meio deste Programa, em 2008, foi criado o Programa Banda Larga nas Escolas, cujo objetivo, como o próprio nome esclarece, é equipar as escolas, que já dispunham de laboratórios de informática, com o recurso de banda larga. 
equipava as escolas com computadores, o Prouca, em funcionamento desde 2005, teve como meta equipar estudantes e professores mediante oferta de laptops para uso individualizado.

Neste ponto, cabe um esclarecimento. Embora o Proinfo ainda se mantenha em funcionamento, desde 2005 , não eram identificados novos investimentos por parte do governo brasileiro em políticas voltadas para a disseminação das tecnologias digitais na educação pública escolarizada. Ao contrário disso, a ausência do Estado ratificou a presença de organizações supranacionais, como a Organização das Nações Unidas para a Educação, Ciência e Cultura (Unesco), aliançadas com empresas privadas, como a Nokia ${ }^{6}$, na elaboração e publicação de diretrizes ${ }^{7}$ para gestores públicos para a elaboração de políticas para o uso de tecnologias na educação. Em 2017, "inspirados [...] nas melhores experiências internacionais" (Proiec, 2018a, p.3), no Brasil, o Ministério da Educação (MEC), em parceria com o Ministério da Ciência, Tecnologia e Inovação (MCTI), lança o Programa de Inovação Educação Conectada (Proiec). O objetivo do Proiec é "apoiar a universalização do acesso à internet em alta velocidade e fomentar o uso pedagógico de tecnologias digitais na educação básica" (Proiec, 2018b, s/p.).

Os documentos relativos às quatro principais políticas direcionadas para a disseminação tecnológica nas escolas públicas brasileiras - Proninfe, Proinfo, Prouca e Proiec - constituem o conjunto de materiais empíricos a partir dos quais foi desenvolvida a analítica aqui apresentada. Conforme expressamos na introdução, utilizamos os conceitos de discurso e subjetivação como ferramentas de análise. Entendemos discursos "como práticas que formam sistematicamente os objetos de que falam" (Foucault, 2009, p. 55).

As práticas discursivas mobilizadas por meio dos documentos analisados foram organizadas em dois eixos analíticos - a saber: desenvolvimento e ensino e aprendizagem -, construídos a partir da identificação e das relações passíveis de serem estabelecidas entre os discursos mobilizados por meio dos documentos analisados. Importa esclarecer que estes eixos estão articulados entre si, de forma que nem sempre é possível classificar determinados discursos em apenas uma das categorias. Entretanto, fica claro o apelo inci-

6 A Nokia é uma empresa multinacional que atua no ramo de tecnologia.

7 É o caso, por exemplo, dos documentos $O$ futuro da aprendizagem móvel: implicações para planejadores de políticas. sivo para o compromisso da educação escolarizada com a meta de desenvolvimento perseguida pelo País. Em outras palavras:

a exigência de novos padrões de produtividade e competividade [...], a visão de que o conhecimento é matéria-prima das economias modernas e que a evolução tecnológica vem afetando não apenas os processos produtivos, mas também as formas organizacionais, as relações de trabalho e a maneira como as pessoas constroem o conhecimento e requerem um novo posicionamento da educação (Proinfo, 1997, p. 2).

As políticas voltadas para a propagação tecnológica na educação, mais do que seguir à risca as propostas de desenvolvimento econômico, desenham a virtualidade. Ao mesmo tempo que produzem o aumento do capital pessoal da população, estas políticas também promovem investimentos na formação do a-orgânico. Com isso, se quer dizer que, por meio de programas educacionais, o estado brasileiro coloca em funcionamento as orientações da Teoria do Capital Humano. No entanto, apenas investimentos individuais não são suficientes. $\mathrm{Na}$ atualidade, a formação de públicos se faz fundamental, e, para tanto, importa fomentar as ações entre os indivíduos, no sentido daquilo que estes são capazes de criar juntos. 0 público "não é um fato social estático e redutível a organismo, mas uma variação, uma tendência, um tornar-se" (Lazzarato, 1999, p. 85). Dessa maneira, "não basta criar infraestrutura para levar tecnologia às escolas. As práticas pedagógicas devem ser orientadas para a inovação nas salas de aula" (Proiec, 2018a, p. 2), pois o mais importante é a capacidade de os sujeitos aprenderem a articular-se uns com os outros.

Dito de outra maneira, queremos demonstrar como os discursos mobilizados pelos programas que propagam a inserção e o uso das tecnologias na educação criam as condições de possibilidade para a produção de modos de ser e de estar no mundo adequados às subjetividades forjadas no neoliberalismo (Lazzarato, 2017). Nas palavras de Rose (2011), a subjetividade diz respeito:

\footnotetext{
aos efeitos de composição e recomposição de forças práticas e relações que se esforçam ou operam para transformar o ser humano em diversas formas de sujeito, que sejam capazes de se constituir em sujeitos de suas próprias práticas, bem como das práticas de outros sobre eles. (p. 236).
}

Compreendemos que os programas de informática na educação nutrem, simultaneamente, a produção do empresário de si mesmo e as relações que os sujeitos são capazes de estabelecer além de um 
tempo estático e de um espaço de encontros físicos. Para este tipo de subjetividade, para "as diferentes formas pelas quais o indivíduo é levado a se constituir como sujeito" (Foucault, 2010, p. 6), tem-se, de um lado, o empresariamento de si e, de outro, "graduações de nível de socialização da economia mundo, sempre mais desterritorializadas e coletivas" (Lazzarato, 1999, p. 88).

Nossas análises do material de pesquisa demonstram que a forma subjetiva produzida pelas práticas discursivas que mobilizam a disseminação e o uso das tecnologias na educação é, entre outros tipos, a do Homo œeconomicus discentis accessibilis. Este tipo de sujeito, além de empresariar a si mesmo, é também um aprendiz por toda a vida e cria as condições para manter-se disponível para acessar e ser acessado em qualquer tempo e lugar. A capacidade de aprender coisas novas e de manter-se em constante processo de aprendizagem torna-se uma das condições para o indivíduo tornar-se empregável e manter-se em condições de empregabilidade.

\section{Aprendizagem e desenvolvimento}

"A escola precisa comprometer-se em promover a capacitação de recursos humanos" (Proninfe, 1989, p. 11) e assumir que "o conhecimento especializado está tendo uma vida média cada vez menor" (Proinfo, 1997, p. 2). 0 novo padrão de desenvolvimento perseguido pelo estado brasileiro impõe a constituição de um "novo cidadão, aquele que deverá colaborar na criação de um novo modelo de sociedade" (Proinfo, 1997, p. 3). Em suma, é esperado "que cada estudante brasileiro possa utilizar as novas tecnologias de forma a obter uma educação plena, que lhe traga desenvolvimento pessoal e que o prepare para ser um agente de desenvolvimento de seu País" (Proiec, 2018a, p. 6). Desse modo, o estado, ao fornecer condições, mesmo que mínimas - como laboratórios de informática, laptops, capacitação dos professores e conectividade -, por meio das práticas discursivas que dissemina, impele alunos e professores a manterem-se conectados à rede, produzindo permanentes investimentos nas atualizações das competências e habilidades individuais. Assim, um número cada vez maior de sujeitos encontra-se apto a participar da racionalidade instaurada.

O fundamento da participação, neste caso, implica aumentar o capital individual para assim melhorar as condições de empregabilidade e a rentabilidade sobre si mesmo. Dessa maneira, promove-se a elevação da renda nacional, que gera mais possibilidades de consumo, mais produção e, por fim, movimentação do mercado. Quanto maiores os investimentos que cada um faz em si mesmo, maiores são as oportunidades de concorrer consigo mesmo e com os outros. Este ciclo, todavia, funciona se cada indivíduo tiver habilidade para avançar a partir dos conhecimentos individuais que é capaz de adquirir. Isso porque, mais do que a capacidade de criar algo sozinho, interessa o que é gerado na virtualidade a partir da articulação com os outros. A potência está no virtual, no que resulta na associação entre os indivíduos. De outra forma, se enfraqueceria a lógica da rede.

Ao assumir que a escola tem "um decisivo papel na retomada do desenvolvimento do País e na construção de um futuro que, sem sombra de dúvidas, será caracterizado pelo domínio [...] da tecnologia" (Proninfe, $1989, \mathrm{~s} / \mathrm{p}$.), o conjunto de ações mobilizadas por meio discursos associados à disseminação digital na educação fomenta a constituição do Homo œeconomicus. 0 culto ao empresariamento de si mesmo é investimento da ordem da individualização. 0 "projeto de substituir o assalariado fordista pelo empreendedor de si, transformando o indivíduo em empresa individual, que gera suas capacidades como recursos econômicos a serem capitalizados, sucumbiu na crise dos subprimes" (Lazzarato, 2017, p. 14, grifos do autor). Isso quer dizer, conforme argumentado por Lazzarato (2017), que tanto países desenvolvidos quanto em desenvolvimento - como é o caso do Brasil - produzem o mesmo tipo de subjetividade que pressupõe maximização da "privatização econômica" e de "individualização subjetiva" (Lazzarato, 2017, p. 14).

O capitalismo pós-moderno impõe a vida a-orgânica (Lazzarato, 1999). 0 a-orgânico pressupõe muito mais "a presença no tempo, e não no espaço" (Lazzarato, 1999, p. 82). 0 tempo, no caso, "não é o tempo abstrato, o tempo medida, mas o tempo-potência" (Lazzarato, 1999, p. 81), o tempo que possibilita criação. 0 tempo que não o do imperativo neoliberal, o tempo do trabalho, mas aquele da contemplação, da arte, da literatura; o tempo que cria as condições de possibilidade para que outras coisas sejam criadas, pensadas, para além da utilidade (Han, 2018). A lógica disciplinar da educação escolarizada, por outro lado, preza o esquadrinhamento do tempo e do espaço e reforma, com isso, as investiduras na individualização dos sujeitos. Diferentemente, os discursos mobilizados pelas políticas de informática na educação ratificam a necessidade de "gerar uma mudança sistêmica nos processos escolares" (Proiec, 2017a, p. 3), pautada no desenvolvimento de "processos mentais elaborados" (Prouca, 2010a, $\mathrm{s} / \mathrm{p}$.). Assim, as práticas discursivas que mobilizam o uso das tecnologias digitais na educação criam 
condições de possibilidade para a constituição de sujeitos que aprendam a desenvolver habilidades e capacidades para compor as redes da atualidade. Para sobreviver na malha da rede neoliberal, não basta ser um empresário de si; é preciso ter competência relacional, criar fluxos que "ultrapassam as distinções entre individual e coletivo" (Lazzarato, 1999, p.84). Portanto, se concorrer é uma necessidade, também se faz fundamental que o indivíduo aprenda, para habitar a rede, a colaborar, a interagir, a criar outra coisa a partir do que já existe. Isso implica assumir a aprendizagem como uma forma de vida. Assim, será melhor se os sujeitos puderem aprender "tanto nos espaços escolares [...] quanto em suas residências" (Prouca, 2010a, s/p.). 0 fomento à ampliação dos espaços de aprendizagem não fica restrito a políticas como o Prouca. Ele também é reverberado nos discursos mobilizados pela parceria Unesco e Nokia, que mencionamos na seção anterior. Para estas agências, programas "do tipo traga o seu próprio dispositivo" (Unesco, 2016a, p. 19) fortalecem a ideia de que;

\section{a aprendizagem contínua ou seamless é uma forma de aprendizagem em que não há interrupções entre os diferentes ambientes - incluindo contextos for- mais e informais. No cenário ideal de aprendizagem contínua, o aluno usa vários tipos de tecnologias de acordo com as oportunidades que surgem, capi- talizando sobre o que cada uma tem a oferecer [...] para manter a continuidade da experiência de aprendizagem [...] (Unesco, 2016a, p. 21).}

Dessa forma, "os imperativos de uma nova ordem econômica e social" (Proninfe, 1989, s/p.) expressos nas políticas de propagação do uso das tecnologias computacionais da educação estão comprometidos com as "novas formas de pensar, trabalhar, viver e conviver no mundo atual, o que muito modificará as instituições educacionais e outras corporações" (Proinfo, 1997, p. 2). Entre as mudanças, talvez a mais significativa seja a ênfase na aprendizagem. As organizações flexíveis, típicas da Contemporaneidade, requerem indivíduos que tenham o comportamento centrado na aprendizagem (Sennett, 2012). Mais do que isso, diante da "multiplicidade de situações de emprego, de não emprego, de emprego intermitente e de pobreza mais ou menos intensa" (Lazzarato, 2017), os investimentos (individuais) em aprendizagem constituem-se nos motores que impulsionam os sujeitos para movimentarem-se na racionalidade da concorrência. Assim, o importante é ser capaz de aprender e aprender ao longo da vida.

Aprendizagem - e seus desdobramentos, como autoaprendizagem, aprendizagem permanente, aprendizagem ao longo da vida - tornou-se um dos conceitos favoritos em políticas nacionais e internacionais (Biesta, 2013) ou "palavra de ordem" (Laval, 2004, p. 47) na intersecção estabelecida entre desenvolvimento econômico e educação. Discursos analisados por Ball (2013) em documentos da Unesco, da Comunidade Europeia, do governo inglês e do sueco demonstram que "no cerne desse fervilhante discurso sobre o aprendiz ao longo da vida está o indivíduo empreendedor" (Ball, 2013, p.145).

A aprendizagem ao longo da vida, entretanto, do modo como é repercutida nessa racionalidade, nada tem a ver com a noção de formação do sujeito no decorrer da vida em uma dimensão ética e estética, que estaria muito mais próxima de uma tradição germânica de bildung, entendida por autores como Hölderlin e Nietzsche como formação, cultivo de si (Weber, 2006), ou como entendida na antiguidade greco-romana - formação como "exercício de inquietar-se consigo mesmo, de vivenciar o cuidado de si, de conhecer-se para ser e para bem viver, de produzir-se a si mesmo como um sujeito singular" (Gallo, 2015, p. 445). A aprendizagem ao longo da vida contemplada na lógica do desenvolvimento neoliberal, por outro lado, está muito mais associada à ideia de eficácia, de performance, que "fazem passar a lógica econômica dentro da lógica escolar em nome de uma representação essencialmente prática do saber útil" (Laval, 2004, pp. 45-46). Aprendizagem ao longo da vida, nesse sentido, está relacionada a desenvolvimento cognitivo, de competências e de habilidades para a solução de problemas.

A centralidade atribuída à aprendizagem, no entanto, não é uma novidade. Noguera-Ramírez (2011), ao ler a modernidade pela perspectiva da educação, afirma que a virada do século XIX para o $\mathrm{xx}$ já havia sido marcada pela passagem do ensino e da instrução para a aprendizagem. Homo discentis é a expressão cunhada por Noguera-Ramírez (2011) para fazer referência à nova forma de subjetivação que produz um tipo de sujeito cujas características são a "responsabilidade pessoal e a autogestão dos próprios riscos e do destino" (Noguera-Ramírez, 2011, p. 16), "um Homo aprendiz permanente, definido por sua condição de ser um aprendiz ao longo da vida" (Noguera-Ramírez, 2011, pp. 16-17). Assim, a "a exigência de novos padrões de produtividade e competitividade" (Proinfo, 1997, p. 2) coloca a aprendizagem no centro dos discursos que promovem o uso das tecnologias digitais na educação, pois, ao assumirem para si a condição de aprendizes ao longo da vida, é esperado que os sujeitos tenham aumentadas as suas "chances de êxito/autonomia na sociedade ativa e produtiva” (Prouca, 2010b, s/p.). 
Todavia, a aprendizagem, nesse contexto que impõe que ela seja dinâmica e constantemente atualizada pela quantidade de informações que pipocam nas telas de computadores, será tanto mais eficiente quanto maiores forem a chances de acesso à conexão em rede. Fomentar "a aprendizagem em qualquer hora, em qualquer lugar" (Unesco, 2016b, p. 16) é uma das recomendações da Unesco e justifica que, "como as pessoas, na maior parte do tempo, levam consigo aparelhos móveis, a aprendizagem pode ocorrer em momentos e em locais que antes não eram propícios à educação" (Unesco, 2016a, p. 16). Aprender fora dos espaços formais de educação torna as pessoas "capaz[es] de melhor individualizar a aprendizagem" (Unesco, 2016a, p. 14).

A situação de aprendizagem, desse modo, coloca no centro do processo o indivíduo, e não mais o sujeito. Ao indivíduo, na relação que estabelece consigo mesmo nesse processo de aprender de forma privada e individualizada, cabe transformar aquilo que aprende em produto, pois este será o seu capital. Com isso, queremos marcar que a aprendizagem, neste "mundo globalmente interligado" (Proninfe, 1989, p. 20) que emerge neste "novo modelo de sociedade" (Proinfo, 1997, p. 6), não é mais priorizada na relação com o outro, em um tempo e espaço coletivos e de compartilhamento de conhecimentos e de pensamento. Ao contrário disso, a noção que emerge na modernidade prioriza os tempos e espaços individuais. Tal individualização produz o esmaecimento da condução pedagógica exercida pelo professor, e isso dificulta que os sujeitos formem repertórios, pois estes são constituídos:

por experiências e encontros que desafiam o ponto de partida, que são verbais mas também são afetivos, corporais, visuais. Fazer parte desse espaço, ver-se cara a cara, comunicar-se, irritar-se e voltar a se escutar, são ações que vão armando outra posição política e também de relação com o saber e a linguagem (Dussel; Masschelein; Simons, 2016, p. 154).

Importa esclarecermos que não queremos negar a aprendizagem, tampouco dizer que ela não pode acontecer em espaços não formais, nem que estes espaços outros, que não são os escolares, não devam ser considerados para este fim. 0 que percebemos é que neste tempo, em que é necessário repensar a escola para o século XXI, parece haver um descompasso entre o que esta instituição tem a oferecer e o que é esperado dela. Queremos assinalar, como demonstra Enzweiler (2017), que há marcas específicas que diferenciam a aprendizagem escolar daquela que acontece em outros espaços onde não há o ensino. 0 viés do ensino presente na aprendizagem escolarizada, explica Enzweiler (2017), traz impressa a "intencionalidade pedagógica", que diferencia a condução exercida pelo professor de "outras formas de condução possíveis" (Enzweiler, 2017, p. 41), como é o caso daquelas exercidas pelo tipo de acesso produzido por meio das tecnologias digitais.

Compreendemos, dessa forma, que o espaço escolar nos mantém, enquanto sujeitos, em um compromisso ético, de partilha e de construção com o outro, e é isso que possibilita a formação de "seres sociais capazes de se comunicar, conviver e dialogar num mundo interativo e interdependente" (Proinfo, 1997, p. 3) e também fora dele. Para nós, a "melhoria da qualidade de vida" (Prouca, 2010b, p. 1) está estreitamente relacionada à aprendizagem escolar, que torna possíveis conhecimentos que não são da ordem da aplicação ou da utilidade. De toda forma, há que se pensar que estamos cada vez mais imersos em uma sociedade cognitiva onde, mais do que aprender conhecimentos específicos, importa aprender habilidades e competências para sobreviver nos nós da rede - neoliberal e da conexão por meio da internet - que compomos.

\section{Considerações}

A analítica que empreendemos por meio da pesquisa aqui discutida faz convergir nosso interesse para discursos publicados pela Unesco que chamam nossa atenção para dois aspectos. 0 primeiro deles está relacionado à omissão do estado brasileiro, por mais de uma década, na atualização e elaboração de políticas para a inserção das tecnologias digitais na educação pública escolarizada. Desse modo, mais do que abrir espaço para organizações supranacionais, em parceria com empresas privadas ${ }^{8}$, emitirem regulações sobre a forma como deve ser conduzido o processo de inserção e uso dos dispositivos digitais na educação, o estado isenta-se do provimento de recursos e das condições necessárias para que os estudantes e professores disponham de tecnologias. Na linha do que propõem as diretrizes da Unesco, que sugerem que cada estudante leve "o seu próprio dispositivo" para a escola (Unesco, 2016a, p. 19), o Proiec é lançado no final do ano de 2017 com o objetivo de ampliar o acesso das escolas públicas à conexão.

O segundo aspecto, fio condutor da discussão que procuramos estabelecer aqui, refere-se à lógica do desenvolvimento, a qual, parece-nos, agora não mais está pautada no desenvolvimento coletivo

8 A parceria entre a Unesco e a Nokia é apenas um exemplo, pois podemos citar também a parceria da Fundação Telefônica Vivo com a Unesco. 
da população, mas no sucesso de cada sujeito em particular. Cada um, individualmente, é conclamado a fazer os investimentos necessários em si mesmo a fim de aumentar seu capital e reverter situações (individuais) de desemprego. Em outras palavras, a "melhoria das condições de desenvolvimento" (Proinfo, 1997, p. 1) deixa de ser uma meta coletiva e passa a ser um status a ser atingido individualmente.

Por essas razões, compreendemos que o tipo de sujeito próprio deste tempo é o Homo œeconomicus discentis accessibilis. Para ele, empresariar a si mesmo já não é mais suficiente; além disso, precisa assumir a condição de aprendiz permanente, e o acesso à conexão em rede deve ser full time. Nessa linha, a ideia de desenvolvimento difundida nas políticas que mobilizam o uso das ferramentas digitais na educação reforça o deslocamento da noção de aprendizagem como formação para a aprendizagem como forma de aquisição de habilidades e competências para a autogestão. Mais do que isso, no Proiec, a noção de desenvolvimento também aparece relacionada com a de inovação. No entanto, inovar, neste caso, não se refere necessariamente a produzir algo novo. De outra forma, inovar, nesse contexto, parece estar mais atrelado à ideia de renovar a si mesmo, de buscar formas de reinventar-se e (sobre)viver na lógica da racionalidade neoliberal, regida pelo consumo e pela falta de postos formais de trabalho.

Tal deslocamento pode ser percebido nos discursos e no tipo de ênfase dada por cada uma das políticas que difundiram o processo deflagrado em 1989 com a propagação da informática na educação. Em 1997, as escolas começam a ser equipadas com laboratórios de informática, e, em 2005, não mais as escolas, mas alunos e professores recebem equipamentos portáteis para uso individual. A partir de 2017 , o governo brasileiro passa a garantir a conectividade, porém a responsabilização pela aquisição de tecnologias mobile para o uso na educação é individual, cabendo aos estudantes e professores. Este movimento, para nós, é representativo da mudança de ênfase que a lógica do desenvolvimento produz na noção de aprendizagem, que nos parece ir na contramão do desenvolvimento científico, tecnológico, das humanidades, das artes, etc. Isso especialmente quando os recursos financeiros liberados no ano de 2017 para o MCTI equivalem, em valores corrigidos pela inflação, a menos de um terço do valor investido no mesmo ministério em $2010^{9}$.

9 Notícia divulgada no site Caderno de Ciência do jornal Estadão, em 17 de julho de 2017. < http://ciencia.estadao.com. $\mathrm{br} / \mathrm{blogs} /$ herton-escobar/orcamento-de-ciencia-e-tecnologia-pode-encolher-ainda-mais-em-2018/>
Para finalizar, entendemos ser fundamental pontuar que há sempre linhas de fuga que nos permitem pensar de outros modos, colocar-nos em movimento e vivenciar diferentes práticas que nos subjetivarão de outras maneiras. Queremos deixar claro que não foi nossa intenção posicionarmo-nos contra o uso das tecnologias na educação. Ao contrário disso, entendemos que é urgente a necessidade de a escola e a universidade reverem suas atuações diante da questão dos avanços tecnológicos.

\section{Referências}

Ball, S. (2013). Aprendizagem ao longo da vida, subjetividade e a sociedade totalmente pedagogizada. Educação,36(2), 144-155. Disponível< http://revistaseletronicas.pucrs.br/ojs/index.php/faced/issue/view/697 > Acesso em 15 de jul. 2013.

Biesta, G. (2013). Para além da aprendizagem: educação democrática para um futuro humano. Belo Horizonte: Autêntica.

Dardot, P.; Laval, C. (2016). A nova razão do mundo: ensaio sobre a sociedade neoliberal. São Paulo: Boitempo.

Dathein, R. (2008). Estado e desenvolvimento no Brasil: o novo padrão de ação estatal como determinante da mudança estrutural da economia no último quarto de século. In: Dathein, R. (Eds.). Desenvolvimento econômico brasileiro. Porto Alegre: UFRGS.

Dussel, I. ; Masschelein, J.; Simons, M. (Org.) (2017). A politização e a popularização como domesticação da escola: contrapontos latino-americanos. Em Larrosa, J. (Org.), Elogio da escola (pp. 147-155). Belo Horizonte .

Enzweiler, D. (2017). Intencionalidade pedagógica: relações entre ensinar e aprender. In: Loureiro, C. B.; Klein, R. R. (Org). Inclusão e aprendizagem: contribuições para pensar as práticas pedagógicas. Curitiba: Appris.

Escobar, A. (2007). La invención del Tercer Mundo: construcción y desconstrucción del desarollo. Bogotá: Norma.

Farias, L. A. E. (2008). Além da estabilização e aquém da estagnação: o Brasil depois do Plano Real In: Dathein, Ricardo (org.). Desenvolvimento econômico brasileiro. Porto Alegre: UFRGS.

Foucault, M. (2008). O Nascimento da Biopolítica. São Paulo: Martins fontes.

Foucault, M. (2009). A arqueologia do saber. Rio de Janeiro: Forense Universitária.

Foucault, M. (2010). Governamentalidade. In: Ditos e escritos IV. Rio de Janeiro: Forense Universitária, 281-305. 
Gallo, S. (2015). Pensar a escola com Foucault: além da sombra da vigilância. In: Carvalho, Alexandre Filordi; Gallo, Sílvio (Orgs.). Repensar a educação: 40 anos após vigiar e punir. São Paulo: Livraria da Física, 427-449.

Han, B. (2018). No enxame: perspectivas do digital. Petrópolis: Vozes.

Klaus, V. (2016).Gestão e Educação. Belo Horizonte: Autêntica.

Klaus, V. (2011). Governamentalidade (Neo)Liberal: da administração para a gestão educacional. Porto Alegre: UFRGS, 2011. Tese (Doutorado em Educação).

Laval, C. (2004). A escola não é uma empresa. 0 neoliberalismo em ataque ao ensino público. Londrina: Planta.

Lazzarato, M. (1999). Para uma definição do conceito de biopolítica . Lugar Comum. Rio de Janeiro, 5-6, 81-96. Disponível em http://uninomade.net/lugarcomum/5-6/

Lazzarato, M. (2017). O governo do homem endividado. São Paulo: n-1 edições.

Loureiro, C. B.; Lopes, M. C. (2017). A constituição do Homo oeconomicus discentes accessibilis. (Texto para discussão). São Leopoldo, RS: UNISINOS.

Moreira, A. F.; Kramer, S. (2007). Contemporaneidade, educação e tecnologia. Educação e Sociedade, 28(100), 1037-1057.

Nied. (1983). Núcleo de Informática Aplicada à Educação - Universidade Estadual de Campinas. Projeto Educom: Proposta Original. Memo n. 1.

Noguera-Ramirez, C. E. (2011). Pedagogia e governamentalidade: ou da Modernidade Educativa como uma sociedade educativa. Belo Horizonte: Autêntica.

Proiec. (2018a). Programa de inovação educação conectada: Conceito. Disponível em < http://portal.mec.gov.br/ index.php?option=com_docman\&view=download $\&$ alias $=77461$ - conceito-do-programa-de-inovacao-educacao-conectada-pdf\&category_slug=novembro-2017pdf\&Itemid=30192 > Acessado em 03 de maio de 2018 .
Proiec. (2018b). Programa de inovação educação conectada: Diretrizes. Disponível em < http://portal.mec.gov.br/ index.php?option=com_docman\&view=download $\&$ alias $=77471$-diretrizes-e-criterios-do-programade-inovacao-educacao-conectada-pdf\&category_ slug=novembro-2017-pdf\&Itemid=30192 > Acessado em 03 de mai de 2018.

Proinfo. (1997). Programa nacional de informática na educação: Diretrizes. Brasília: Ministério da Educação e do Desporto.

Proninfe. (1989). Programa nacional de informática educativa: Documento orientador. Brasília: Ministério da Educação e do Desporto.

Prouca. (2010a). Programa um computador por aluno: Manual. Disponível em < www.uca.gov.br/institucional//dowloads/manual_eletronico.pdf > Acessado em 04 de dez. de 2010.

Prouca. (2010b). Programa um computador por aluno: resolução/FNDE/CD/no 17 de 10 de junho de 2010.

Rose. N. (2011). Inventando nossos Selfs: psicologia, poder e subjetividade. Petrópolis, RJ: Vozes.

Sennett, R. (2012). A corrosão do caráter: consequências pessoais do trabalho no novo capitalismo. Rio de Janeiro: Record.

Sibilia, P. (2012). Redes ou paredes: a escola em tempos de dispersão. Rio de Janeiro: Contraponto.

Unesco. (2016a). Diretrizes de políticas para a aprendizagem móvel. Disponível em < www.unesco.org/openacces/terms-use-ccbyncnd-port $>$ Acesso em 05 de maio de 2016.

Unesco. (2016b). O futuro da aprendizagem móvel: implicações para planejadores e gestores de políticas. Disponível em <http://unesdoc.unesco.org/ images/0022/002280/228074POR.pdf > Acesso em 05 de maio de 2016.

Weber, J. F. (2006). Bildung e educação. Educação e Realidade, 31( 2), 117-134. 